\title{
Trypsinogen activation peptides (TAP) concentrations in the peritoneal fluid of patients with acute pancreatitis and their relation to the presence of histologically confirmed pancreatic necrosis
}

\author{
D I Heath, C Wilson, A M Gudgeon, A Jehanli, A Shenkin, C W Imrie
}

\begin{abstract}
This study measured the volume and colour, as well as concentrations of trypsinogen activation peptides (TAP) in the peritoneal fluid of 22 patients with acute pancreatitis and related these findings to the presence of pancreatic necrosis. Nine patients had a severe attack with histologically confirmed pancreatic necrosis, seven a severe attack without confirmed necrosis, and six a mild attack, also without confirmed necrosis. A free fluid volume $>20 \mathrm{ml}$ or free fluid colour > grade 5 on the Leeds chart, or both detected histologically confirmed pancreatic necrosis with a sensitivity of $100 \%$ and specificity of $31 \%$. A total peritoneal fluid TAP concentration of $\geqslant 96 \mathrm{nmol}$ detected histologically confirmed pancreatic necrosis with a sensitivity of $89 \%$ and specificity of $85 \%$, figures comparable with contrast enhanced computed tomography. These findings suggest that the measurement of peritoneal fluid TAP concentrations can detect effectively histologically confirmed pancreatic necrosis and that such measurements may prove useful in the selection of patients for surgery.

(Gut 1994; 35: 1311-1315)
\end{abstract}

One of the principal factors determining the outcome of an attack of acute pancreatitis is the presence of pancreatic necrosis. ${ }^{1-4}$ This occurs in 10 to $15 \%$ of patients and is associated with a death rate of 30 to $40 \%{ }^{4-8}$ For this reason its early identification and prompt treatment remains an important priority in the treatment of acute pancreatitis.

It has been suggested, although it remains

Accepted for publication 7 January 1994 unproved, that pancreatic necrosis only develops where intraglandular trypsinogen activation occurs. ${ }^{910}$ If this is the case then we would expect to see a correlation between the presence and extent of pancreatic necrosis and the serum concentration of trypsin, in patients with acute pancreatitis. Failure to show such a relation in the past may result from the failure of the immunoreactive trypsin assay to differentiate between the active enzyme (trypsin) and the parent zymogen (trypsinogen). ${ }^{11}$ This problem has been overcome recently by the development of an immunoassay using antibodies directed against the $C$ terminal end of the trypsinogen activation peptides (TAP) and which reports the activation of the zymogen. ${ }^{12} \mathrm{We}$ have shown previously the effectiveness of urinary TAP measurements in determining the severity of acute pancreatitis. ${ }^{13}$ In this study we examine the ability of TAP concentrations, measured in peritoneal fluid, to detect histologically confirmed pancreatic necrosis.

\section{Methods}

PATIENTS

A consecutive series of 309 patients with acute pancreatitis were reported prospectively between February 1986 and July 1989. A diagnosis of acute pancreatitis was made on the basis of a serum amylase greater than $720 \mathrm{IU} / 1$ (equivalent to a value of $1200 \mathrm{IU} / \mathrm{l}$ as measured by the Phadebas method), in the presence of a compatible clinical picture of the disease. Patients, who were considered, on clinical assessment at the time of admission to hospital, to have moderate or severe acute pancreatitis were entered into a randomised trial comparing standard conservative treatment plus intraperitoneal aprotinin treatment, with standard conservative treatment alone. One hundred and four patients fulfilled the entry criteria as outlined above. Fifty four (51\%) patients were randomised to receive standard conservative treatment alone, did not have peritoneal aspiration, and will not be considered further. The remaining $50(49 \%)$ patients were randomised to the treatment group and had peritoneal aspiration. It is this group of patients that are examined in this study.

In two patients it was realised, after peritoneal aspiration, that the initial diagnosis 
TABLE II Complications in 22 patients with acute pancreatitis who had diagnostic peritoneal aspiration and lavage. The number of complications was greater than the number of patients as one patient may suffer more than one complication

\begin{tabular}{lll}
\hline & $\begin{array}{l}\text { Pancreatitis with } \\
\text { confirmed necrosis } \\
\text { (9 patients) }\end{array}$ & $\begin{array}{l}\text { Severe pancreatitis } \\
\text { without confirmed } \\
\text { necrosis (7 patients) }\end{array}$ \\
\hline Remplications & 2 & 5 \\
Renal failure & 1 & 1 \\
Confirmed pancreatic & & \\
necrosis & 9 & - \\
Pancreatic collection & 2 & - \\
Pancreatic pseudocyst & 1 & - \\
Pancreatic abscess & 2 & - \\
Died & 5 & - \\
\hline
\end{tabular}

of acute pancreatitis was incorrect: one had a traumatic transection of the pancreas and the other extensive mesenteric venous infarction. They, and one further patient who refused peritoneal aspiration after randomisation, were withdrawn from the study. Free peritoneal fluid was aspirated from $26(55 \%)$ of the remaining 47 patients and a sufficient volume of fluid was available for analysis in 22 of these. There was insufficient fluid available for analysis in the four remaining patients.

Nine patients were classified retrospectively as suffering from a severe attack of acute pancreatitis with confirmed pancreatic necrosis (five from specimens obtained at postmortem examination and four from specimens obtained at the time of surgery), seven as having severe disease without confirmed necrosis, and six as having mild disease, also without confirmed necrosis (Table I).

The three patient groups were comparable in terms of age, sex, aetiology, and hospital stay (Table I). The prolonged median stay and lack of differences in the length of hospital stay between the patient groups, was because of two patients with mild disease who remained in for a cholecystectomy and another who had a delayed discharge for social reasons. Table II shows the complications suffered by patients with severe disease.

Intraperitoneal aprotinin treatment failed to influence the mortality or morbidity of acute pancreatitis $^{14}$ : $48(48 \%)$ patients suffered a mild and $53(52 \%)$ a severe outcome.

\section{PERTTONEAL ASPIRATION}

Peritoneal aspiration was performed with an 8 French gauge peritoneal dialysis catheter (Kimal Scientific Products Ltd, Uxbridge, England), which was inserted into the peritoneal cavity through a small subumbilical stab incision, after the infiltration of local anaesthetic. Any free fluid was aspirated and its volume and colour recorded as described previously. ${ }^{15}$ It was centrifuged at $4^{\circ} \mathrm{C}$ within

TABLE III Details of the peritoneal fluids from 22 patients with acute pancreatitis who had diagnostic peritoneal aspiration and lavage. The ranges are shown in brackets

\begin{tabular}{|c|c|c|c|}
\hline & $\begin{array}{l}\text { Severe pancreatitis } \\
\text { with confirmed } \\
\text { necrosis }\end{array}$ & $\begin{array}{l}\text { Severe pancreatitis } \\
\text { without confirmed } \\
\text { necrosis }\end{array}$ & $\begin{array}{l}\text { Mild pancreatitis } \\
\text { without confirmed } \\
\text { necrosis }\end{array}$ \\
\hline \multirow{2}{*}{$\begin{array}{l}\text { Median fluid volume }(\mathrm{ml}) \\
\text { Median fluid colour } \\
\text { Median TAP (nmol//) } \\
\text { Median TAP } \times \text { fluid volume } \\
\text { (nmol) }\end{array}$} & $\begin{array}{l}140(60-1120) \\
8(6-8) \\
4 \cdot 08(0 \cdot 42-21)\end{array}$ & $\begin{array}{l}120(11-900) \\
6(3-8) \\
0.33(0-1.68)\end{array}$ & $\begin{array}{l}21 \cdot 5(10-210) \\
4(3-5) \\
0.00(0-0.4)\end{array}$ \\
\hline & $442(41-4570)$ & $17(0-840)$ & $0(0-84)$ \\
\hline
\end{tabular}

one hour of being taken, frozen, and stored at $-20^{\circ} \mathrm{C}$ until analysis. The median (range) times between the onset of symptoms and peritoneal aspiration were 23 hours ( 14 to 58 ) for patients with confirmed necrosis, 23 hours (2 to 101) for patients with severe attacks but without confirmed necrosis, and 26 hours (15 to 39) for patients with mild attacks. These differences were not significant $(\mathrm{H}=0.66$, df (degrees of freedom $)=2$, $\mathrm{p}=0 \cdot 719$, Kruskal-Wallis test).

ASSAYS

\section{Trypsinogen activation peptide (TAP)}

The TAP assay was performed in duplicate in the department of surgery, St George's Hospital Medical School, London. Frozen peritoneal fluid samples $(300 \mu \mathrm{l})$ were thawed, mixed with an equal volume of $25 \mathrm{mmol} / \mathrm{l} \mathrm{TRIS} / \mathrm{HCL}$ buffer, $\mathrm{pH} 7 \cdot 4$, containing $0.15 \mathrm{~mol} / 1 \mathrm{NaCl}, 10 \mathrm{mmol} / 1 \mathrm{EDTA}$, $2.5 \mathrm{mg} / \mathrm{ml}$ bovine serum albumin, and $20 \mathrm{mmol} / \mathrm{l} \mathrm{NaN}$, and incubated in a boiling water bath for 10 minutes. The samples were centrifuged at $1000 \mathrm{~g}$ for five minutes and the supernatants $(100 \mu \mathrm{l})$ assayed for TAP as described by Hurley et al. ${ }^{12}$

\section{Amylase}

Measurements of serum amylase concentrations were made on a Hitachi 737 random access discrete analyser (Mannheim, Germany) using an enzymatic colorimetric assay ( $\alpha$-amylase PNP (Mannheim, Germany). The normal range was 0-200 IU/1 and the within batch precision was $1.01 \%$ at an amylase of $1129 \mathrm{IU} / 1$.

\section{STATISTICAL ANALYSIS}

Data were analysed using medians, the Mann-Whitney U test, Fisher's exact test, and Kruskal-Wallis test as appropriate. To avoid repetition in the text the Mann-Whitney U test has been used unless stated otherwise. Confidence intervals were used in preference to $\mathrm{p}$ values in judging the relevance of differences. ${ }^{16}$

The total amount of TAP contained within the peritoneal fluid was calculated by multiplying the free fluid TAP concentration by the total volume of fluid aspirated.

\section{Results}

TAP CONCENTRATION

The distribution of TAP concentrations within the three groups was not uniform $(\mathrm{H}=13 \cdot 10$, $\mathrm{df}=2, \mathrm{p}=0.001$, Kruskal-Wallis test) (Table III). Significantly higher TAP concentrations were seen in the peritoneal fluid of patients with severe pancreatitis associated with confirmed necrosis when compared with patients with severe disease but without confirmed pancreatic necrosis $(95.6 \% \mathrm{CI}=0.4$ to $9.0 \mathrm{nmol} / \mathrm{l}, \mathrm{p}<0.4)$ or those with mild 


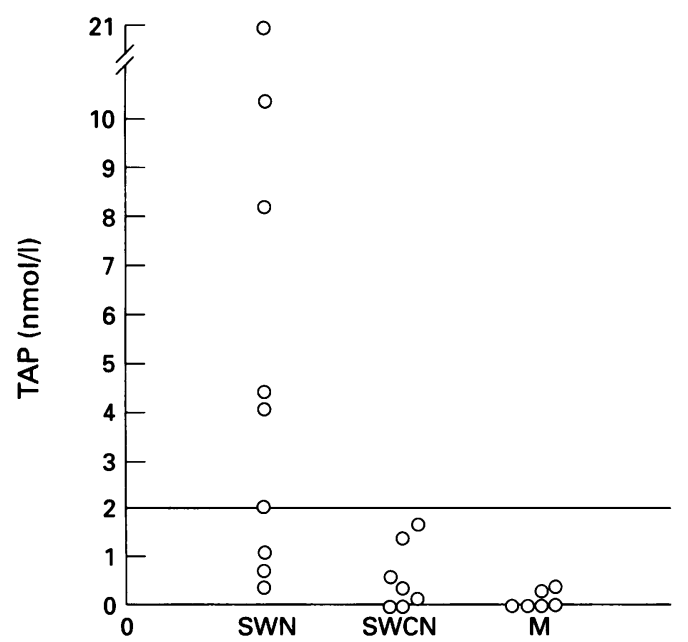

Figure 1: Free peritoneal fluid TAP concentrations in nine patients with severe pancreatitis with histologically confirmed necrosis ( $S W N$ ), seven patients with severe acute pancreatitis without histologically confirmed necrosis $(S W C N)$, and six patients with mild disease (M).

disease $(96 \cdot 1 \% \quad \mathrm{CI}=0.68$ to $10.4 \mathrm{nmol} / \mathrm{l}$, $\mathrm{p}<0.006)$. Significant differences were not seen between patients with severe attacks without confirmed necrosis and mild attacks $(96.2 \% \mathrm{CI}=-0.07$ to $1.4 \mathrm{nmol} / \mathrm{l}, \mathrm{p}<0.5)$. Using a peritoneal fluid TAP concentration of $\geqslant 2 \mathrm{nmol} / \mathrm{l}$ (Fig 1) we could distinguish between necrotising and other forms of acute pancreatitis with a sensitivity of $67 \%$ (six of nine patients) and specificity of $100 \%$ (13 of 13 patients).

The distribution of the total TAP content of the free peritoneal fluid within the three groups was not uniform $(\mathrm{H}=11.75, \mathrm{df}=2, \mathrm{p}=0.003$ (adjusted for ties), Kruskal-Wallis test) (Table III). Significantly higher total TAP concentrations were seen in the peritoneal fluids of patients with severe pancreatitis associated with confirmed necrosis when compared with patients with severe disease but without confirmed pancreatic necrosis $(95.6 \%$ $\mathrm{CI}=25.8$ to $2100.0 \mathrm{nmol}, \mathrm{p}=0.026)$ or those with mild disease $(96 \cdot 1 \% \mathrm{CI}=96 \cdot 1$ to $2444 \cdot 0$ $\mathrm{nmol}, \mathrm{p}=0.0024)$. Significant differences were not seen between patients with severe attacks without confirmed necrosis and mild attacks $(96 \cdot 2 \% \mathrm{CI}=-8.6$ to $630 \cdot 0 \mathrm{nmol}, \mathrm{p}=0 \cdot 15)$.

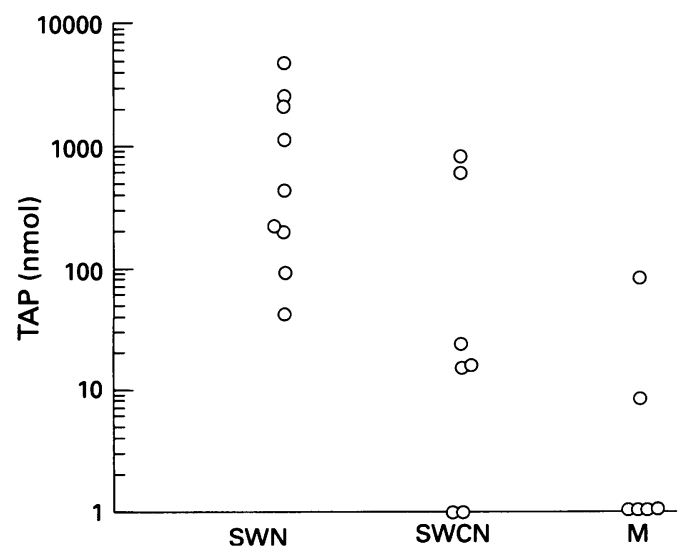

Figure 2: Total free peritoneal fluid TAP concentration in nine patients with severe pancreatitis with histologically confirmed necrosis ( $S W N$ ), seven patients with severe acute pancreatitis without histologically confirmed necrosis $(S W C N)$, and six patients with mild disease (M).
Using a cut off value of $96 \mathrm{nmol}$ we could detect pancreatic necrosis with a sensitivity of $89 \%$ and specificity of $85 \%$ (Fig 2 ).

\section{FLUID VOLUME}

The distribution of fluid volumes within the three groups was not uniform $(\mathrm{H}=6 \cdot 47, \mathrm{df}=2$, $\mathrm{p}=0.04$, Kruskal-Wallis test) (Table III). There were no significant differences in the volume of fluid obtained from patients with severe attacks with confirmed necrosis and severe attacks without confirmed necrosis $(95.6 \% \mathrm{CI}=-390 \cdot 1$ to $189.1 \mathrm{ml}, \mathrm{p}<0.75)$ or between those with severe attacks without confirmed necrosis and mild attacks $(96 \cdot 2 \%$ $\mathrm{CI}=-4 \cdot 1$ to $490 \mathrm{ml}, \mathrm{p}<0 \cdot 22)$. Significant differences were seen, however, between patients with severe attacks with confirmed necrosis and mild attacks $(96 \cdot 1 \% \mathrm{CI}=34.9$ to $225 \mathrm{ml}, \mathrm{p}<0 \cdot 05)$. A free fluid volume of $>20$ $\mathrm{ml}$ predicted pancreatic necrosis with a sensitivity of $100 \%$ (nine of nine patients) but the specificity of only $38 \%$ (four of 13 patients).

\section{FLUID COLOUR}

The distribution of fluid colour between the three groups was not uniform $(H=13.62$, $\mathrm{df}=2, \mathrm{p}=0.001$, Kruskal-Wallis test) (Table III). Significant differences were noted in the colour of fluid samples between those patients with severe attacks with and without confirmed necrosis $(95.6 \% \quad \mathrm{CI}=0$ to 5 , $\mathrm{p}<0.03$ ) and severe attacks with confirmed necrosis and mild attacks of acute pancreatitis $(96 \cdot 1 \% \mathrm{CI}=3$ to $5, \mathrm{p}<0 \cdot 003)$. Significant differences were not seen, however, in the fluid colour between patients with severe attacks but without confirmed necrosis and mild attacks of acute pancreatitis $(96.2 \% \quad \mathrm{CI}=-1.0$ to 3 , $\mathrm{p}=0 \cdot 3)$. A free fluid colour of greater than grade 5 selected patients with pancreatic necrosis with a sensitivity of $100 \%$ (nine of nine patients) and a specificity of only $46 \%$ (six of 13 patients).

Where a patient had $>20 \mathrm{ml}$ of free fluid aspirated or free fluid colour darker than grade 5 , or both pancreatic necrosis was detected with a sensitivity of $100 \%$ and specificity of $31 \%$.

Table IV summarises the sensitivity, specificity, predictive values, and percentage correct for the above parameters.

\section{Discussion}

While the Ranson and Glasgow criteria provide effective separation between mild and severe attacks of acute pancreatitis, they cannot identify accurately patients with necrotising disease. ${ }^{17} 18$ Clinical assessment ${ }^{51920}$ and visual inspection of the gland at the time of surgery have also proved ineffective. ${ }^{5}$ Nordback et $a l^{5}$ failed to show any correlation between the extent of histologically confirmed pancreatic necrosis and blood glucose, serum sodium, potassium, creatinine, calcium, triglycerides, bilirubin or transaminases, packed cell volume, white cell or platelet 
TABLE IV Summary of the sensitivity, specificity, predictive values, and percentage correct of peritoneal free fluid volume, colour, TAP concentrations, and total TAP content in determining the presence of pancreatic necrosis in 22 patients with acute pancreatitis

\begin{tabular}{|c|c|c|c|c|c|}
\hline & $\begin{array}{l}\text { Sensitivity } \\
(\%)\end{array}$ & $\begin{array}{l}\text { Specificity } \\
(\%)\end{array}$ & $\begin{array}{l}+v e \\
P V(\%)\end{array}$ & $\begin{array}{l}-v e \\
P V(\%)\end{array}$ & $\begin{array}{l}\% \\
\text { Correct }\end{array}$ \\
\hline $\begin{array}{l}\text { TAP } \geqslant 2 \mathrm{nmol} / 1 \\
\text { Free fluid volume }>20 \mathrm{ml} \\
\text { Fluid colour }>\text { grade } 5 \\
>20 \mathrm{ml} \text { of free fluid or colour }>\text { grade } 5 \\
\text { Median TAP } x \text { fluid volume }\end{array}$ & $\begin{array}{r}67 \\
100 \\
100 \\
100 \\
89\end{array}$ & $\begin{array}{r}100 \\
38 \\
62 \\
31 \\
85\end{array}$ & $\begin{array}{r}100 \\
50 \\
64 \\
50 \\
80\end{array}$ & $\begin{array}{r}81 \\
100 \\
100 \\
100 \\
92\end{array}$ & $\begin{array}{l}86 \\
59 \\
77 \\
59 \\
86\end{array}$ \\
\hline
\end{tabular}

+ve $P V=$ positive predictive value, +ve $P V=$ negative predictive value.

counts. While a number of studies have suggested that RNAse, ${ }^{2122} \alpha_{1}$-antiprotease, $\alpha_{2}$-macroglobulin, ${ }^{23}$ calcium, ${ }^{24} 25$ and $\mathrm{C}$ reactive protein ${ }^{2326}$ are effective in detecting pancreatic necrosis, others have failed to confirm these findings. $5101526-28$ Ultrasound examination of the pancreas has also proved ineffective. ${ }^{20} 29$

At present, contrast enhanced computed tomography provides the best method of detecting pancreatic necrosis, an area of hypoperfusion being equated with the presence of necrotic tissue. ${ }^{20}{ }^{30-32}$ Using these criteria Buchler et $a l^{23}$ have claimed that contrast enhanced computed tomography detects pancreatic necrosis with an accuracy of $85-90 \%$ and more recently Larvin et $\mathrm{al}^{32}$ have identified correct:y 11 patients with histologically confirmed necrosis. Forty patients with equivocal or normal enhancement recovered without the need for surgery. Computed tomography is, however, not universally available, entails moving a sick patient away from intensive care, and is comparatively expensive. For these reasons alternative methods of detecting pancreatic necrosis have been sought. If, as has been suggested, pancreatic necrosis only develops where intraglandular trypsinogen activation occurs, then the measurement of urinary or peritoneal fluid TAP concentrations may detect effectively its presence. ${ }^{910}$ While we have shown previously the presence of TAP in the urine of patients with severe acute pancreatitis, ${ }^{13}$ this is the first time that TAP has been measured in the peritoneal fluid of patients.

The closest similarity to the selection criteria used in this study was provided by a multicentre trial of peritoneal aspiration reported by Corfield et al ${ }^{19}$ in which patients with predicted severe disease had peritoneal aspiration. Twenty seven per cent of patients reported had either $>20 \mathrm{ml}$ of free fluid or fluid darker than grade 5 compared with $38 \%$ in this series. The presence of $>20 \mathrm{ml}$ of free peritoneal fluid, fluid of colour $>$ grade five or a combination of the two could not detect histologically confirmed pancreatic necrosis with a specificity high enough to make them of clinical value. This failure agrees with the findings of a study by Larvin and McMahon ${ }^{33}$ who noted that a free fluid volume $>40 \mathrm{ml}$ or fluid the colour of 'prune juice' could only detect pancreatic necrosis with a sensitivity of $72 \%$ and specificity of $84 \%$.

Peritoneal fluid TAP concentrations were noted to be significantly higher in patients with severe acute pancreatitis who had confirmed necrosis than in either of the other two groups. The sensitivity of peritoneal fluid TAP concentrations in detecting histologically confirmed pancreatic necrosis was too low to be clinically useful. A positive predictive value of $100 \%$, however, meant that it did identify correctly all patients with histologically confirmed necrosis. When the peritoneal fluid TAP concentration was multiplied by the free peritoneal fluid volume, a TAP concentration $>96 \mathrm{nmol}$ detected pancreatic necrosis with a sensitivity and specificity comparable with the gold standard: contrast enhanced computed tomography. 82032 Confirmation that peritoneal fluid TAP concentrations do correlate with disease severity comes from animal experiments. ${ }^{34} 35$ In a study of rats with caerulin induced pancreatitis, the greatest pool of TAP was found within the free peritoneal fluid, concentrations here being significantly higher in non-survivors than in survivors. ${ }^{35}$ A total peritoneal fluid TAP concentration of $70 \mathrm{pmol} / 1$ predicting the outcome in $94 \cdot 1 \%$ of animals. Furthermore, peritoneal fluid TAP concentrations proved to be an indicator of the histopathological severity of the disease, TAP concentrations correlating with the presence of intrapancreatic haemorrhage $(r=0.57)$ and acinar cell necrosis $(r=0 \cdot 72)$.

The reason why raised concentrations of TAP were found in those patients without confirmed necrosis is unclear. It is possible that a degree of trypsinogen activation occurs in oedematous acute pancreatitis. Recently Yamaguchi ${ }^{36}$ has described, for the first time, trypsinogen activation in rats with caerulin induced pancreatitis put under stress. Fernandez del Castillo et $a l^{34}$ have confirmed these findings by detecting TAP in the urine of rats with caerulin induced pancreatitis. It may be that a similar situation arises in humans. It is also possible that a number of those patients without histologically confirmed necrosis had undetected pancreatic necrosis. Contrast enhanced computed tomography was unavailable during the study period and so it is not possible to exclude pancreatic necrosis in these patients. Despite this it should be remembered that the presence of pancreatic necrosis showed on contrast enhanced computed tomography is not an absolute indication for surgical intervention. A number of authors have shown that even patients with extensive areas of pancreatic hypoperfusion can recover with conservative treatment alone. ${ }^{17} 313738$ In addition it is generally agreed that the decision to operate should be based upon a combination of computed tomography findings and assessment of the patients general condition; those with computed tomography confirmed necrosis and a deteriorating clinical condition, or evidence of pancreatic or peripancreatic sepsis being considered suitable for debridement. ${ }^{39}$ Therefore, we can see that we need to identify correctly those patients with pancreatic necrosis who will require surgery rather than those simply with pancreatic necrosis. In this study a total peritoneal fluid 
TAP concentration $>96 \mathrm{nmol} / \mathrm{l}$ identified correctly eight of nine patients who either had or might have benefited from surgery.

In common with other authors' experience 15194041 we failed to identify correctly, using clinical evaluation at the time of admission to hospital, a number of patients who were subsequently shown to have suffered a severe attack of acute pancreatitis. This failure will reduce the sensitivity of peritoneal fluid TAP measurements in detecting histologically confirmed pancreatic necrosis. This may, however, not be an important drawback as very few of the patients coming to surgery have an operation during the first week after admission to hospital. If peritoneal fluid TAP concentrations were being used as a means of selecting those patients requiring surgery, then a delay of 48 hours or longer before prediction became available would be acceptable. Such a strategy would also have the advantage of restricting the number of mild cases undergoing peritoneal aspiration. Peritoneal aspiration, when used as a means of severity assessment, has never been accepted widely into clinical practice, perhaps because of its interventional nature and the risk of visceral perforation. ${ }^{15}$ If it were possible, however, to identify pancreatic/peripancreatic necrosis, or patients who required surgery, then the balance of risks and benefits would shift in favour of peritoneal aspiration.

While this preliminary study suggests that the measurement of peritoneal fluid TAP concentrations can identify patients with confirmed pancreatic necrosis and help in selecting those patients requiring surgery, it should be noted that these findings are retrospective and will require confirmation in a prospective manner before being adopted into clinical practice.

1 Uhl W, Buchler $M$, Malfertheiner $\mathrm{P}$, Martini $M$, Berger HG. PMN-elastase in comparison with CRP, antiproteases, and LDH as indicators of necrosis in human proteases, and LDH as indicators of necro

2 Bradley EL, Murphy F, Ferguson C. Prediction of pancreatic necrosis by dynamic pancreatography. Ann Surg 1989; 210: 495-503.

3 Leger L, Chiche B, Louvel A. Pancreatic necrosis and acute pancreatitis. World f Surg 1981; 5: 315-7.

4 Hollender LF, Meyer C, Keller D. Planned operation for necrotising pancreatitis: the continental experience. In Howard JM, Jordan GL, Reber HA, eds. Surgical diseases of the pancreas. 1986. Philadelphia: Lea \& Febinger, $450-60$.

5 Nordback I, Pessi T, Auvinen O, Autio V. Determination of necrosis in necrotizing pancreatitis. Br F Surg 1985; 72: 225-7.

6 Edelman G, Boutelier P. Le Traitement Des Pancreatities Aigues Necrosantes Par L'ablation Chirurgicale Precoce Des Portions Necrosees. Chirurgie 1974; 100: 155-9.

7 Kivilaakson E, Fraki O, Nikki P, Lempinen M. Resection of the pancreas for acute fulmunant pancreatitis. Surg Gynecol Obstet 1981; 152: 493-8.

8 Beger HG, Bittner R, Block S, Buchler M. Bacterial contamination of pancreastic necrosis. A prospective clinical study. Gastroenterology 1986; 91: 433-8.

9 Hermon Taylor J, Heywood GC. A rational approach to the specific chemotherapy of pancreatitis. Scand Gastroenterol Suppl 1985; 117: 39-46.

10 Rinderknecht H. Activation of pancreatic zymogens: normal activation, premature intrapencreatic activation, protective mechanisms against inappropriate activation. Dig Dis Sci 1986; 24: 80-6.

11 O'Conner CM, O'Donnell MD, McGeeney KF. Problems associated with the radioimmunoassay of serum trypsin. Clin Chim Acta 1980; 114: 29-35.

12 Hurley PR, Cook A, Jehanli A, Austen BM, Hermon-Taylor J. Development of radioimmunoassays for free tetraJ. Development of radioimmunoassays for free tetra-
aspartyl-L-lysine trypsinogen activation peptides (TAP). f Immunol Methods 1988; 111: 195-203.
13 Gudgeon AM, Heath DI, Hurley P, Jehanli A, Patel G, Wilson $\mathrm{C}$, et al. Trypsinogen activation peptides assay in the early prediction of severity of acute pancreatitis. Lancet 1990; 335: 4-8.

14 Lavin $M$, Wilson $C$, Heath $\mathrm{D}$, Alexander D, Imrie CW, McMahon MJ. Intraperitoneal aprotinin therapy and the clinical course of acute pancreatitis. Br f Surg 1992; 79: clinical

15 McMahon MJ, Playforth MJ, Pickford IR. A comparative study of methods for the prediction of severity of attacks study of methods for the prediction of severity
of acute pancreatitis. Br F Surg 1980; 67: 22-5.

16 Gardner MJ, Altman DG. Statistics with confidence confidence intervals and statistical guidelines. London: BMJ Publishing Group, 1989

17 Teerenhovi O, Nordback I, Isolauri J. Ranson signs and necrosis of the pancreas in acute necrotising pancreatitis. Acta Chir Scand 1988; 154: 385-8.

18 Leese T, Shaw D, Holliday M. Prognostic markers in acute pancreatitis: can pancreatic necrosis be predicted? Ann $R$ Coll Surg Engl 1988; 70: 227-32.

19 Corfield AP, Cooper MJ, Williamson RC, Mayer AD, McMahon MJ, Dickson AP, et al. Prediction of severity in acute pancreatitis: prospective comparison of three progacute pancreatitis: prospective comparis

20 Block S, Maier W, Bittner R, Buchler M, Malfertheiner P, Beger HG. Identification of pancreas necrosis in severe acute pancreatitis: imaging procedures versus clinical staging. Gut 1986; 27: 1035-42.

21 Warshaw AL, Lee KH. Serum ribonuclease elevations and pancreatic necrosis in acute pancreatitis. Surgery 1979 86: $227-34$.

22 Warshaw AL, Fournier P. Release of ribonuclease from anoxic pancreas. Surgery 1984; 95: 537-40.

23 Buchler M, Malfertheiner P, Beger HG. Correlation of imaging procedures, biochemical parameters and clinical stage in acute pancreatitis. In: Malfertheiner $P$, Ditschuneit $\mathrm{H}$, eds. Diagnostic procedures in pancreatic disease. Berlin: Springer-Verlag, 123-9.

24 Edmondson HA, Berne CJ. Calcium changes in acute pancreatic necrosis. Surg Gynecol Obstet 1944; 79: 240-4.

25 Edmondson HA, Berne CJ, Homann RE, Wertman M Calcium, potassium, magnesium and amylase disturbances in acute pancreatitis. $A m$ f Med 1952; 12: 34-42.

26 Puolakkainen P, Valtonen V, Paananen A, Schroder T. $\mathrm{C}$-reactive protein (CPR) and serum phospholipase A2 in the assessment of the severity of acute pancreatitis. Gut 1987; 28: 764-71.

27 Wilson C, Heads A, Shenkin A, Imrie CW. C-reactive protein, antiproteases and complement factors as objective markers of severity in acute pancreatitis. Br f Surg 1989; 76: $177-81$.

28 Kemmer TP, Malfertheiner P, Buchler M, Kemmer ML Ditschuneit $H$. Serum ribonuclease activity in the diagnosis of pancreatic disease. Int $\mathcal{F}$ Pancreatol 1991; 8: diagnosis

29 Swobodnik W. Controversies and limitations of ultrasonog raphy in acute pancreatitis. In: Malfertheiner $P$ Ditschuneit $\mathrm{H}$, eds. Diagnostic procedures in pancreatic disease. Berlin: Springer-Verlag, 1986: 32-6.

30 Kivisaar L, Somer K, Standertskjold Nordenstam CG Schroder T, Kivilaakso E, et al. A new method for the diagnosis of acute hemorrhagic-necrotizing pancreatitis using contrast-enhanced CT. Gastrointest Radiol 1984; 9. $27-30$.

31 Nuutinen P, Kivisaari L, Schroder T. Contrast-enhanced computed tomography and microangiography of the pancreas in acute human hemorrhagic/necrotizing pancreaticreas in acute human hemorrha
tis. Pancreas 1988; 3: 53-60.

32 Larvin M, Chalmers AG, McMahon MJ. Dynamic contras enhanced computed tomography: a precise technique for identifying and localising pancreatic necrosis. $B M \mathcal{F} 1990$ 300: $1425-8$

33 Larvin M, McMahon MJ. 'Prune Juice' peritoneal fluid in patients with acute pancreatitis: is the pancreas necrotic? Gut 1986; 27: A230-1.

34 Fernandez del Castillo C, Schmidt J, Rattner DW Lewandrowski K, Compton CC, Jehanli A, et al. Generation and possible significance of trypsinogen activation peptides in experimental acute pancreatitis in the rat. Pancreas 1992; 7: 263-70.

35 Schmidt J, Fernandez del Castillo C, Rattner DW, Lewandrowski K, Compton CC, Warshaw AL. Trypsinogen activation peptides in experimental rat panTrypsinogen activation peptides in experimental rat pancreatitis: prognostics and histopath
Gastroenterology 1993; 103: 1009-16.

36 Yamaguchi H, Kimura T, Mimura K, Nawata $H$ Activation of proteases in caerulin-induced pancreatitis. Pancreas 1989; 4: 565-71

37 White TT, Heimbach DM. Sequestrectomy and hyperalimentation in the treatment of hemorrhagic pancreatitis. Am F Surg 1976; 132: 270-5.

38 Smadja $\mathrm{C}$, Bismuth $\mathrm{H}$. Acute necrotic pancreatitis: toward restriction of surgical indications. Gastroenterol Clin Biol 1984; 8: $536-40$

39 Beger HG. Management of pancreatic necrosis and pancreatic abscess. In: Carter DC, Warshaw AI, eds. Pancreatitis. Edinburgh: Churchill Livingstone, 1989.

40 Larvin M, McMahon MJ, APACHE-II score for assessment and monitoring of acute pancreatitis. Lancet 1989; ii: and $201-5$.

41 Wilson C, Heath DI, Imrie CW. Prediction of outcome in acute pancreatitis: A comparative study of APACHE II, acute pancreatitis: A comparative study of APACHE II,
clinical assessment and multiple factor scoring systems. Br F Surg 1990; 77: 1260-4. 